\title{
Slum Rehabilitation with Fast Track Techniques
}

\author{
R.R.Sorate ${ }^{1}$, Alka Dhiman ${ }^{2}$, Ashwini Murnal ${ }^{2}$, Manali Nimbalkar², \\ Nutan Dere ${ }^{2}$, Vandana Tiwari ${ }^{2}$ \\ ${ }^{I}$ Assistant Prof., Department of civil engineering, Sinhgad Academy of Engineering, India \\ ${ }^{2}$ Student, Department of civil engineering, Sinhgad Academy of Engineering, India
}

\begin{abstract}
Slum is an area with heavy population living in substandard housing which lacks basic and civics amenities. Urbanization, growing population and migration pressurizes cities leading to overflowing infrastructure, increase in urban poverty and haphazard development of cities. Thus rehabilitation of slum is necessary to provide fair and affordable houses to slum dwellers.

Fast track techniques proved to be useful to serve the purpose. Fast track techniques are associated with using methods that reduce the project overlapping and total duration of the project at sustainable finance. This paper focuses on fast track techniques like Tunnel form and Rapidwall compared with recent in use technique Aluform in terms of cost, duration, benefits and their utility in Indian conditions.

Fast track techniques are necessary as rehabilitation is long term process including costly affairs which generates problems to slum dwellers and ultimately to the country. Tunnel form and Rapidwall helps in reducing rehabilitation time by completing the project in optimum cost and duration.
\end{abstract}

Keywords: Aluform, fast-track techniques, rapid wall, slum rehabilitation, tunnel form

\section{Introduction}

According to census data 2011, 65 million people live in the slum in India and may rise to 104 million by 2017. As the population of India multiplies, it contributes to the growth of slums. In the entire country, Maharashtra consists of large number of slum pockets. In the state, 1.81 crore population is residing in slum dwellings and if the conditions aren't brought under control or measures aren't taken to uplift the standard of living of the people, the census 2011 projects this number to grow upto 2.05 crores by 2017. Pune is one of the most important cities of Maharashtra which is developing at a fast rate, attracting the population all around the country this is leading to urbanization, industrialization and inadequate amenities to all, which are the major reasons for the slum formation. Pune has 3.5 million population out of which $43 \%$ of its population living in the slum, i.e. about 210,000 families reside in 564 slums in the city.

The development of the country is measured in terms of the standard living of the people residing in it. For a city to be developed the rehabilitation of the slums is very necessary. The paper aims at rehabilitation of the slum with fast track techniques and procedures to reduce overall time and cost of the project, to encourage the involvement of private developers to uplift the slums. An attempt has been made to examine the effectiveness of two newly introduced construction techniques viz., Tunnel form and Rapid wall technology with respect to current, majorly in use technique, Aluform for slum rehabilitation in terms of time, cost and resources.

\section{Rationale And Significance}

Slum rehabilitation can be defined as, "rebuilding the homes, improving the standard of living of the group of people living under deprived conditions of basic amenities like adequate living area and shelter, water, sanitation and electricity".

Due to large urbanization population of cities is increasing leading to lack of equal opportunities making rich people richer and poor people poorer resulting in increased lower income groups. Land is a fixed asset which cannot increase with demand and is proving to be a challenge to satisfy the housing demand of our country leading to haphazard settlement. The land meant for residence when used for industries or vice versa leads to formation of slum due to negligence in planning of housing arrangements for labours and workers.

For overall development of the city, eradication and rehabilitation of the slums is very important for which several government and non-government organizations are working. Slum rehabilitation is a social service with benefits in terms of TDR(Transferable Development Rights) for developers who are involved, if the time and cost of construction of slum rehabilitation is reduced without comprising with its quality,then more and more private developers will be encouraged. This way the slums are removed, slum dwellers get a better place to reside, developers are in profit and the city is developed. 


\section{Review Of Literature}

A. Aluform

Aluform technology is majorly used technique in current construction scenario, it is simple and easily adaptable. Due to the easy adaptation of the technique it is very suitable for the Indian construction as it is labour intensive and India has abundant labours. The formwork is pre-engineered and pre-planned to the finest details. Being made up of aluminium, it is light weight and can be easily carried manually. This technique leads to a monolithic construction, where walls, columns and slab are cast in one continuous pour. It involves initial investment for manufacturing of forms but due to its higher repeatability than the conventional formwork (around 250) it is more feasible.

\section{Methodology -}

Aluform needs to be set for a period of 1 month before the actual construction work starts according to the authorized plan and panel number for respective walls.

The Aluform technique usually follows 4 step cycle:-

Erect vertical formwork and reinforcement bars for entire or part of floor.

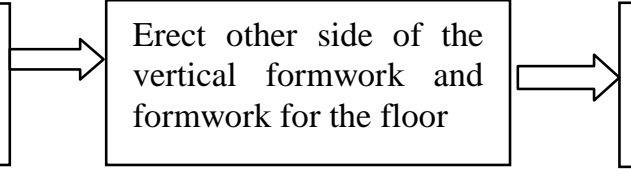

Leave props for 7 days and floor slab formwork in place for 2.5 days.
Reinforce the floor slabs and concreting of walls and slabs is done

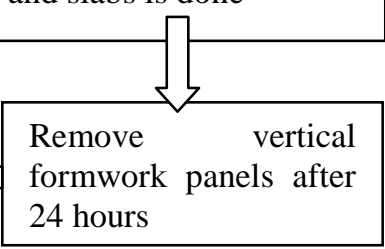

P.P. Pattanshetti, H.B. Patil concluded that the Aluform technique gives high quality construction at a higher speed with reasonable cost. But Ms. Dhanshree Patil and Prof. Desai believe that, the construction imposes large work load and responsibility on labours.

\section{B. Rapidwall technology}

Rapid wall technology is an innovation of Australia and is proving to be of great benefit in current housing shortage and rapid environmental degradation. It is an alternative technology used for construction of buildings with usage of rapid walls which are all also known as gypcrete panels or GFRG panels (Glass Fibre Reinforced Gypsum). These rapidwall panels are made up of gypsum which may either be naturally occurring or may be large amount of waste from the fertilizer industry. In India, FACT and RCF, two major fertilizer manufacturing factories have taken the initial steps in introducing this technique and have set up rapid wall and plaster manufacturing factories under the name of FACT RCF Building Products Ltd.(FRBL) in Cochin and Mumbai. Rapid wall technology used by IIT MADRAS as a low cost and fast track construction technique for construction of a test building was the inspiration for using the same for slum rehabilitation. Rapid wall, which is still under the research for its suitability for high rise building but it has been tested by IIT Madras and certified by Structural Engineering Research Centre (SERC) for use in the construction of buildings up to 10 storey's.

Erection process

After completion of the foundation or the concrete suspended floor onto which Rapidwall is to be positioned, establish and mark all main grid lines.

Pre-Panel Installation:

Check the horizontal level with the help of auto level and set out the wall locations with respect to the main grid lines and according to the architectural plan. Plinth beam is drilled and the starter bars are epoxies and the DPC is applied. These starter bars are extended further.

Lifting, Propping, Tieing :

From the stillages, respective rapidwalls are lifted with the help of a crane and positioned on the set out wall location and the walls are propped. Vertical reinforcement bars are inserted and tied with the starter bars. 
Concrete the rapidwall cavities according to the design.

Seal the openings of the cavities and fix the door, window frames.

Shuttering of slab:

Position the panels horizontally over the walls, cavities are cut out and the micro-beams are placed and concreting is done upto $50 \mathrm{~mm}$ thickness.

Devdas menon, A .Meher Prasad(October 2013) conclude that the GFRG panel can be used for construction with confidence because of the adequate shear strength, stiffness, ductility and energy dissipation capacity.

Maganti Janardhan, Devdas menon, A .Meher Prasad carried out finite element buckling analysis and concluded that the failure of panel occurs neither due to buckling nor due to in-plane axial and shear load as critical loads are much higher than usual practices.

\section{Tunnel formwork}

Tunnel form is a box type structural system which is composed of RC shear walls and slabs constructed monolithically. It is made up of mild steel and hence has a substantial salvage value upto $30 \%$.

It was first adopted by France company, Outinord. Tunnel form was further developed and largely adopted by Turkey. Tunnel form is useful for slum rehabilitation as it is mainly used for mass housing having identical structural units. It has enhanced earthquake resistance, speed in construction and economy in high rise buildings. It is highly mechanized and hence less number of labours are required. Brickwork is required for some internal walls and external walls which cannot be cast by tunnel formwork, thus creating leakage problems.

\section{Methodology}

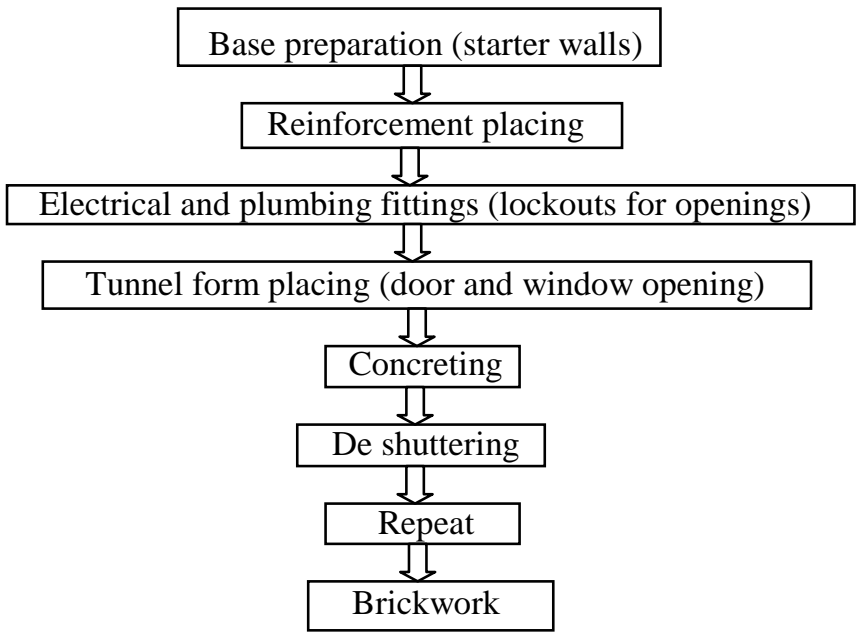

Zeynep Yesim Ilerisoy, Mehmet Emin Tuna (2013) This paper concludes that use of tunnel form is justified in high rise buildingsM.Wallace (1985), It gives the methodology to be followed for construction of buildings using tunnel form.

Yaser Sotoudeh, mozhdeh salehi, saeed moradzadeh, homayoon taghipoor, meisam behboodi (2013) The paper gives the detailed advatanges and disadvantages of tunnel form

\section{Aim And Objective}

For rapid development of the city, eradication and rehabilitation of the slums is important as it improves the living habits of the people dwelling in the slums, and hence a clean, hygienic and a developed city. Following are the research objectives:

- To study slum scenario of the Pune city.

- To find out most economical, fast and feasible construction technique for rapid slum rehabilitation

- To propose the developers, to use these new and alternate construction techniques for the rehabilitation projects to save time and money. 


\section{Problem Statement}

Urbanization, industrialization and poverty leads to formation of slum which gives rise to haphazard growth of the city and unhygienic conditions in certain areas of the city, and hence proves to be the barrier to the overall development of the city. The current process of slum rehabilitation is very slow and lengthy and therefore becomes less profitable. To rehabilitate the slums, the dwellers have to be shifted temporarily to another place until the completion of the project which adds largely to the cost of the project and holds up the land which could have used for other development work. Because of all this reasons, the need for fast track technique was realized and needed to be implemented.

\section{Research Methodology}

- Identify the slums in the Pune city and establish the need for rehabilitation.

- Study the scenario of the slums in Pune and current rehabilitation projects

- Overview of rules and regulations of the SRA scheme and developers working under it.

- Study the current techniques used for the rehabilitation projects and need for better and rapid techniques.

- Identify and search the fast track, new and economical techniques and find their applications in the rehabilitation projects.

- Study of Rapid wall technology and Tunnel form for their suitability.

- Comparison of these new techniques with the current, majorly in use technique, Aluform with respect to Time, Money and Resources

\section{CASE STUDY}

To study the effectiveness of these techniques and compare these techniques, case study was undertaken.

$>$ Project: Slum Rehabilitation project for PRATHAMA Building

$>$ Location: Ram tekdi, Hadapsar, Pune

$>$ Developer: Naik Navare Developers( Patent for aluform in Pune)

$>$ Building under study is $\mathrm{G}+10$ constructed by Aluform technique, experimental investigation was carried out for $\mathrm{G}+2$, only for superstructure.

- To propose a model slum rehabilitation project, for the city development.

\section{Results}

After studying the plans and procedures, determining the resources required, scheduling the activities and preparing the approximate estimation and comparing three Tunnel form and Rapidwall technique with respect to Aluform technique, the results are presented in Table :

Table no.1: Comparison of Tunnel form and Rapidwall with respect to Aluform.

\begin{tabular}{|c|c|c|c|}
\hline CRITERIA & ALUFORM TECHNIQUE & TUNNELFORM TECHNIQUE & $\begin{array}{l}\text { RAPIDWALL } \\
\text { TECHNIQUE }\end{array}$ \\
\hline Concrete saving & - & $\begin{array}{l}\text { Less } \\
20 \%\end{array}$ & $\begin{array}{l}\text { More } \\
60 \%\end{array}$ \\
\hline Steel saving & - & $\begin{array}{l}\text { Very less } \\
3 \%\end{array}$ & $\begin{array}{l}\text { More } \\
40 \%\end{array}$ \\
\hline Brick requirement & - & $\begin{array}{l}\text { Required } \\
20-30 \%\end{array}$ & No \\
\hline Wall panel & Not requied & Not required & $\begin{array}{l}\text { Required } \\
\text { Cost- } 700 / \mathrm{m}^{2}\end{array}$ \\
\hline Initial investment & $\begin{array}{l}\text { More } \\
\text { Set of aluform } \\
9000 / \mathrm{m}^{2}\end{array}$ & $\begin{array}{l}\text { Very high } \\
\text { Tunnel form } \\
45000 / \mathrm{m}^{2}\end{array}$ & No initial investment \\
\hline Time saving & Time required is more & $65 \%$ & $66 \%$ \\
\hline Labour cost & Labours required high & Less & Less \\
\hline $\begin{array}{ll}\text { Suitability } & \text { for } \\
\text { highrise } & \\
\end{array}$ & Suitable upto 25 floors & Suitable for 45 storey & $\begin{array}{l}\text { Suitable for } 10 \text { floors } \\
\text { As per BMPTC }\end{array}$ \\
\hline $\begin{array}{l}\text { Environmental } \\
\text { concern }\end{array}$ & Less & Less & $\begin{array}{l}\text { More, and can be } \\
\text { reused }\end{array}$ \\
\hline Necessity of cranes & Optional & Must & Must \\
\hline Formwork repetition & 150-250 times & $800-1200$ times & - \\
\hline Props requirement & More & Moderate & Less \\
\hline
\end{tabular}


Results of study of all three techniques with respect to material cost, total cost and total duration showing the savings.
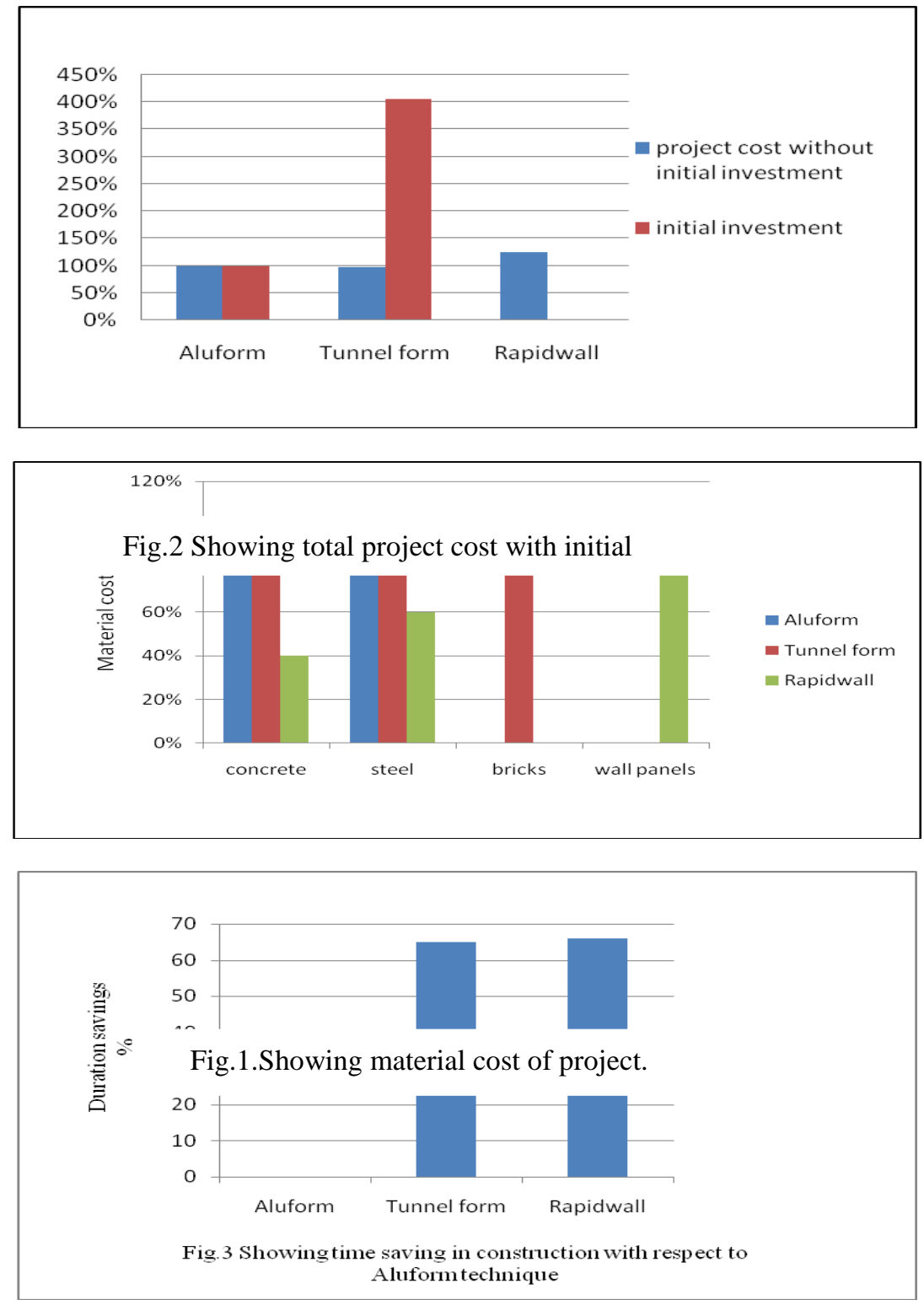

\section{Conclusion}

- Rapidwall is a low cost and fast track technique which leads to saving of resources, time and money. It can be used in the areas which have been struck with calamities and for restoring the lifeline of the area rapidly.

- In today's world of environmental degradation, where resources are exploited, rapidwall technology is a boon as it is manufactured from the waste gypsum from the fertilizer companies. Though the money is spent on Rapidwall as a resource, it is $100 \%$ reusable and leads to saving of other resources and hence proves economical.

- Rapid wall doesn't need formwork and is a easy erection process and leads to light weight structure.

- Rapidwall technique is a pre-planned construction technique where openings are cut in the factory itself where they are manufactured.

- Rapid wall is very suitable for low rise and low earthquake zones.

- Rapidwall technique is ideal for construction of slum rehabilitation projects where low rise buildings or individual dwellings are to be constructed with high speed and where there is shortage of resources.

- Tunnel formwork is a very effective technique for high rise buildings and therefore suitable for the cities which are developing vertically where the land is at short. 
- Tunnel form technology is ideal for earthquake prone areas and hence its large initial investment proves to be economical in such areas.

- Tunnel formwork system is highly mechanized, requires less man power and hence not readily adaptable in India where population is high , cheap and abundant labour is available.

- Brickwork is necessary in Tunnel form construction, hence continuity breaks and therefore more suitable for commercial buildings than residential buildings

- Though tunnel formwork has high initial investment, the number of repetitions of the formwork is high too, therefore the tunnel formwork proves to be economical in long run and therefore can be used extensively in slum rehabilitation projects where identical units and blocks are constructed.

- Capital is not tied and hence enhances rolling of capital when Tunnel form and Rapid wall system is used, benefitting the developers.

\section{References}

[1] 131128 Rapidwall Installation Manual by Rapid building system pty ltd .

[2] A. Tavafoghi and S. Eshghi (2008), Seismic Behaviour of Tunnel Form Concrete Building Structures.

[3] Census data 2011

[4] Devdas Menon, A Meher Prasad (Dept of Civil Engineering, IIT Madras), Development of Building, Systems using Glass Fibre Reinforced Gypsum (GFRG) Panels.

[5] M.Wallace, cast walls and slab at the same time with tunnel forms.

[6] Maganti Janardhan, A. Meher Prasad and Devdas Menon, studies on the behavior of glass fiber reinforced gypsum wall panels.

[7] Miss. Patil Dhanashri Suryakant, Prof. Desai D B, "Emerging Trends in Formwork - Cost Analysis \& Effectiveness of Mivan Formwork over the Conventional Formwork

[8] Yaser Sotoudeh, mozhdeh salehi, saeed moradzadeh, homayoon taghipoor, meisam behboodi, (2013), Building technology for mass concrete tunnel form method.

[9] Zeynep Yesim Ilerisoy, Mehmet Emin Tuna (2013), Construction cost of tunnel form buildings. 